\title{
Molecular Mapping of a Recessive Powdery Mildew Resistance Gene in Wheat Cultivar Tian Xuan 45 Using Bulked Segregant Analysis with Polymorphic Single Nucleotide Polymorphism Relative Ratio Distribution
}

\author{
Kaixiang Chao,,${ }^{1,2}$ Wenwen Su, ${ }^{1}$ Lei Wu, ${ }^{1}$ Bei Su, ${ }^{1}$ Qiang Li,, $1+$ Baotong Wang, ${ }^{1, \dagger}$ and Dongfang $\mathrm{Ma}^{3}$ \\ ${ }^{1}$ State Key Laboratory of Crop Stress Biology for Arid Areas, College of Plant Protection, Northwest A\&F University, Yangling, 712100 \\ Shaanxi, China; ${ }^{2}$ College of Chemistry Biology and Environment, Yuxi Normal University, Yuxi, 653100, Yunnan, China; and ${ }^{3}$ Hubei \\ Collaborative Innovation Center for Grain Industry, Yangtze University, Jingzhou, 434025 Hubei, China
}

Accepted for publication 24 September 2018.

\begin{abstract}
Powdery mildew is a destructive foliar disease of wheat worldwide. Wheat cultivar Tian Xuan 45 exhibits resistance to the highly virulent isolate HY5. Genetic analysis of the $F_{2}$ and $F_{2: 3}$ populations of a cultivar Ming Xian 169/Tian Xuan 45 cross revealed that the resistance to HY5 was controlled by a single recessive gene, temporarily designated as PmTx45. A Manhattan plot with the relative frequency distribution of single nucleotide polymorphisms (SNPs) was used to rapidly narrow down the possible chromosomal regions of the associated genes. This microarray-based bulked segregant analysis (BSA) largely improved traditional analytical methods. PmTx45 was located in chromosomal bin

4BL5-0.86-1.00 and was flanked by SNP marker $A X-110673642$ and intron length polymorphism (ILP) marker ILP-4B01G269900 with genetic distances of 3.0 and $2.6 \mathrm{cM}$, respectively. Molecular detection in a panel of wheat cultivars using the markers linked to PmTx45 showed that the presence of PmTx45 in commercial wheat cultivars was rare. Resistance spectrum and chromosomal position analyses indicated that PmTx45 may be a novel recessive gene with moderate powdery mildew resistance. This new microarray-based BSA method is feasible and effective and has the potential application for mapping genes in wheat in marker-assisted breeding.
\end{abstract}

Powdery mildew is one of the most damaging diseases of wheat (Triticum aestivum L.) worldwide. It is caused by Blumeria graminis (DC.) E.O. Speer f. sp. tritici Em. Marchal (referred to as B. graminis f. sp. tritici hereafter) and occurs in wheat growing regions with moist and cold conditions. Powdery mildew can reduce crop yield by more than $30 \%$ and can seriously damage the quality of the grain when it is prevalent (Griffey et al. 1993; Leath and Bowen 1989). Improving wheat resistance to powdery mildew is an environmentally friendly and cost-effective method to control the hazards of powdery mildew (Nelson et al. 2018). One of the strategies to improve wheat resistance is via marker-assisted selection during breeding, so that disease-resistant genes can be stably inherited and expressed in new cultivars. However, it is challenging to breed effective, stable, and broad-spectrum resistant wheat cultivars because the resistance can be lost fairly quickly as a result of the rise of virulent pathogen populations (Mundt et al. 2002). However, pyramiding multiple resistance genes into a cultivar can achieve durable resistance in crops (Singh et al. 2008). Thus, the identification of more resistance genes from broad and various sources is a long-term and important work.

To date, more than 70 genes resistant to powdery mildew have been identified and located in wheat chromosomes, and they are officially named from Pml ascending to Pm58 (McIntosh et al. 2017). Six of

${ }^{\dagger}$ Corresponding authors: Q. Li; E-mail: qiangli@nwsuaf.edu.cn, and B. Wang; E-mail: wangbt@nwsuaf.edu.cn

Funding: This research was supported by the National Key R\&D Program of China (grants 2016YFD0300705, 2018YFD0200403, and 2018YFD0200501), the Technical Guidance Project of Shaanxi Province (grant 2017CGZH-HJ-01), the National Science Foundation of China (grant 31501620), and the China Ministry of Education 111 Project (grant B07049)

*The $\boldsymbol{e}$-Xtra logo stands for "electronic extra" and indicates that one supplementary table is published online.

The author(s) declare no conflict of interest.

(C) 2019 The American Phytopathological Society these loci (Pml, Pm3, Pm4, Pm5, Pm8, and Pm24) have more than one resistance allele. Among these officially named genes, $P m 5$ (Pm5a to Pm5e) (Hsam et al. 2001; Huang et al. 2003), Pm9 (Schneider et al. 1991), Pm26 (Rong et al. 2000), Pm42 (Hua et al. 2009), and Pm47 (Xiao et al. 2013) confer recessive resistance. The existence of these recessive resistance genes enriches the resistance mechanism to powdery mildew and provides more resources for resistance breeding ( $\mathrm{Fu}$ et al. 2013). In addition, recessive disease resistance genes have an advantage of individual plant selection in the breeding process, as the individual containing a homozygous recessive resistance gene can be accurately identified by phenotype. This also means that individual plants with an allele for a dominant gene and a heterozygous gene are more susceptible to disease.

Bulked segregant analysis (BSA), which works with two selected and pooled groups that display extreme opposing phenotypes for a trait of interest, has been widely used for mapping target genes (Zou et al. 2016). To map a resistance gene, two bulked samples are created by pooling the DNA of resistant individuals and susceptible individuals, respectively. By comparing the two bulks, polymorphism markers can be screened out for further molecular mapping, and others can be eliminated to reduce the cost of experimentation (Michelmore et al. 1991). The advent of nextgeneration sequencing technologies enables efficient highthroughput discovery of DNA variants in wheat, and new generation markers, such as single nucleotide polymorphisms (SNPs), which provide high resolution of genetic diversity (Wang et al. 2018). Combining high-throughput genotyping technology with a BSA strategy is an emerging powerful tool for accelerating gene identification and quantitative trait loci mapping (Zou et al. 2016). Of these genotyping platforms, genotyping by sequencing (GBS) has been widely used in the mapping and application of disease resistance genes (Zou et al. 2016). For example, Yin et al. (2018) used BSA combined with a locus amplified fragment (SLAF) sequencing strategy to rapidly identify a stripe rust resistance gene in space-induced wheat mutant R39. A total of 45 resistant plants and 45 susceptible plants selected from the cultivar 
Ming Xian 169/R39 $\mathrm{F}_{2}$ population were bulked as the resistant bulk and the susceptible bulk used for SLAF sequencing to fine-map the stripe rust resistance gene $\operatorname{YrR39}$ to a $17.39-\mathrm{Mb}$ segment on chromosome 4B. Although GBS has advantages in fine-mapping and map cloning of disease resistance genes, BSAs with individual DNA makers and microarrays are always the first choice for preliminary research materials because of their low cost. Using BSA with polymerase chain reaction (PCR)-based markers (including randomly amplified polymorphic DNA, the sequence tagged site, the sequence characterized amplified region, restriction fragment length polymorphism, and other markers), polymorphic markers between two parents and two bulks were selected by screening a large number of markers covering the genome for the construction of linkage maps. For example, to locate $P m 47,967$ simple sequence repeat (SSR) markers were examined between resistant and susceptible parents and bulks, from which four SSR markers on chromosome 7BS displayed polymorphism and were linked to the resistance gene. Thus, $P m 47$ was initially located on chromosome 7BS (Xiao et al. 2013). However, PCR-based BSA is labor intensive and it is very difficult to locate the target genes on the specific chromosomal regions in a short time. Microarray-based BSA, which genotypes two parents and two bulks by the chip, is a high-throughput method and the number of polymorphism markers can be identified in a short time, which is more efficient than the PCR-based methods (Zou et al. 2016). However, a large number of polymorphic markers also creates a problem-namely, how to rapidly determine the location of the target gene on the chromosome. The current method is to initially determine the chromosomes of the target gene by counting the number of polymorphism SNPs on each chromosome or calculating the percentage of polymorphism SNPs in all SNPs of the chip on each chromosome, and then compare the reference genetic maps or physical maps, count the number of polymorphic markers per centimorgan of base or megabase, and use the markers that are selected from the largest number of intervals for linkage analysis to construct the genetic map (Wu et al. 2017). This general analysis of the polymorphic SNP site-enrichment method has a disadvantage. Because the number of SNPs per chromosome on each different type of the microarray is not evenly distributed, the number of SNP distributions on the same chromosome is also uneven, meaning that the target gene may exist in the intervals that have a lower number of SNPs. This method may lead to difficulty in quickly selecting the marker to use for mapping in certain cases. Thus, it is necessary to improve the method of preliminary judgment of a gene location by chips. This study will address this issue.

Wheat cultivar Tian Xuan 45 (original code 919R, Gansu wheat variety approval number 2009011) was developed by the Tianshui Agricultural Science Institute of Gansu Province in China. The pedigree of Tian Xuan 45 is 15 th12 and 8845-1-1. Tian Xuan 45 exhibits all-stage resistance to the predominant Chinese stripe rust races (CYR), including CYR29, CYR32, CYR33, and CYR34 (Cao et al. 2017), and we also found that it had seedling resistance to powdery mildew in our tests.

The objectives of this study were as follows: (i) to identify the resistance gene to powdery mildew in Tian Xuan 45, (ii) to characterize the powdery mildew resistance gene(s) in Tian Xuan 45 using molecular markers to construct genetic and physical maps, and (iii) to develop a method for preliminarily determining the chromosomal location of the resistance gene loci through microarray-based BSA.

\section{MATERIALS AND METHODS}

Plant materials. Wheat cultivar Tian Xuan 45, as the male parent, was crossed with susceptible cultivar Ming Xian 169 to develop a mapping population for genetic analysis of the powdery mildew resistance and mapping the resistance gene. Fifteen plants of the $F_{1}$ generation, 105 plants of the $F_{2}$ population, its $F_{2: 3}$ population, and the two parents were used to identify the powdery mildew resistance gene(s) for seedling resistance in Tian Xuan 45. Thirty-two differential hosts with the known resistance genes, which were provided by the wheat powdery mildew research group of the Chinese Academy of Agricultural Sciences Institute of Plant Protection, and 103 commercial varieties were used to identify the infection types of the B. graminis f. sp. tritici isolates. Each isolate was purified from a single conidiospore in this study to ascertain the range of its pathogenicity.

Pathogen isolates and evaluation of powdery mildew response. A total of 238 leaf samples with B. graminis f. sp. tritici were randomly collected from adult plants from more than 30 fields in Shaanxi Province $\left(31^{\circ} 42^{\prime}\right.$ to $39^{\circ} 35^{\prime} \mathrm{N}, 105^{\circ} 29^{\prime}$ to $111^{\circ} 15^{\prime} \mathrm{E}$, $205,800 \mathrm{~km}^{2}$ ) from April to May in 2013 and 2014 powdery mildew epidemic seasons. The method used to obtain isolates derived from single ascospores of samples was performed as described by Niewoehner and Leath (1998). For the sexual cleistothecium, the spore release was required before purification. First, leaf fragments with cleistothecium, which were cut from each sample, were placed in Petri dishes with distilled water for 2 to 3 days. Then single cleistothecium was transferred to a small piece of filter paper that was attached to a Petri dish cover. Fresh, sterile wheat leaf segments from a susceptible variety were neatly arranged in the Petri dish with $0.5 \%$ water agar medium (containing benzimidazole at $60 \mu \mathrm{g} / \mathrm{ml}$ ). It was ensured that only one piece of filter paper with a single cleistothecium was in each Petri dish. The Petri dishes were then sealed and placed in a greenhouse with $16 \mathrm{~h}$ of light and $8 \mathrm{~h}$ of dark exposure at 17 to $18^{\circ} \mathrm{C}$. When the powdery mildew was fully developed on the leaf fragments, it was inoculated to seedlings of the susceptible variety planted in pots $10 \mathrm{~cm}$ in diameter for continual culture. Each pot was separated to ensure the purity of the isolates. When ascospores just appeared and the spores were not released, the leaf segments containing ascospores were cut off to allow for a single ascospore to be transferred to a small filter paper. Then the previous steps were repeated two or three times. This method allowed us to obtain purified B. graminis f. sp. tritici isolates. These purified $B$. graminis f. sp. tritic $i$ isolates continued to be cultured on susceptible seedlings. For leaf samples with viable conidia, they were directly inoculated to powdery mildew free seedlings for culture by simply shaking. The purification steps were as mentioned above (Parks et al. 2008, 2009; Xia et al. 2005). In this study, wheat cultivar Ming Xian 169 was used to culture $B$. graminis f. sp. tritici isolates.

All of the isolates were identified by the 32 differential hosts using the leaf fragment method in vitro. Each host was planted in pots filled with a mixture of farmyard manure and sandy loam soil. When the seedlings had grown to the two-leaf stage, several $3.0-\mathrm{cm}$ leaf segments from each host were placed on the surface of separate Petri dishes containing $0.5 \%$ water agar medium with

TABLE 1. The virulence formula of four Blumeria graminis f. sp. tritici isolates of wheat powdery mildew at the seedling stage

\begin{tabular}{ll}
\hline Isolate & \multicolumn{1}{c}{ Virulence formula $^{\mathrm{a}}$} \\
\hline HY5 & $1,4,5,7,12,14,15,17,30$ \\
HX4 & $1,4,5,14,19$ \\
MX20 & $1,8,9,10,13,14,18,19,22,26,27,30$ \\
CCQ15 & $1,4,7,14,15,19$ \\
\hline
\end{tabular}

a The 32 known differential hosts with their resistance genes included in parentheses are as follows: 1, Axminster/8Cc (Pm1); 2, Ulka/8Cc (Pm2); 3, Asosan/8Cc $(P m 3 a) ; 4$, Chul/8Cc $(P m 3 b)$; 5, Sonora/8Cc $(P m 3 c)$; 6, Kolibri (Pm3d); 7, W150 (Pm3e); 8, Mich Amber/8Cc (Pm3f); 9, Khapli/8Cc $(P m 4 a) ; 10$, Armada $(P m 4 b) ; 11$, Aquila $(P m 5 b) ; 12$, Timgalen (Pm6); 13, Cokerc747 (Pm6); 14, CI14189 (Pm7); 15, Kavkaz (Pm8); 16, R4A (Pm13); 17, Amigo (Pm17); 18, MIN (Pmlc); 19, XX186 (Pm19); 20, Yangmai5/ Sub.6V (Pm21); 21, Chiyacao (Pm24); 22, 5P27 (Pm30); 23, CI12632 (Pm2+6); 24, Maris Dove $(P m 2+M l d) ; 25$, Maris Huntsman $(P m 2+6+?) ; 26$, Kenguie 1 (Pm4+8); 27, Mission $(P m 4 b+5 b)$; 28, Baitu 3 (Pm4+?); 29, Cokerc983 $(P m 5+6) ; 30$, Nonrandie $(P m 1+2+19) ; 31$, Era (PmEra); and 32, Xiaobaidongmai $(P m X B D)$. 
benzimidazole at $60 \mathrm{mg} / \mathrm{liter}$. Each Petri dish was inoculated with conidia from a single $B$. graminis $\mathrm{f}$. sp. tritici isolate cultured on the leaf of Ming Xian 169 by shaking. Three replicate plates were inoculated with each isolate. The culture conditions of these dishes were as described above. Infection types were scored 14 days after inoculation using the following ratings: 0 , no visible spots; 0 ; necrotic reactions or dead spots could be seen on the leaves, but the leaves had no sporulation; 1 , a bit of the colony could be seen on the leaves but the diameter of each was less than $1 \mathrm{~mm}$, and sparse aerial hypha and little sporulation also could be seen on the leaves; 2 , the diameter of the colonies was less than $1 \mathrm{~mm}$ but moderate aerial hypha and sporulation could be seen on the leaves; 3 , thick aerial hypha and abundant sporulation were observed, and the diameter of the colonies was greater than $1 \mathrm{~mm}$, but the lesion was not continuous; and 4, thick aerial hypha and abundant sporulation were present, and lesions were continuous. Infection types 0,$0 ;, 1$, and 2 were considered as resistant, and types 3 and 4 as susceptible (Sheng 1988).

Four B. graminis f. sp. tritici isolates (HY5, MX20, HX4, and CCQ15) were selected from the total 238 B. graminis f. sp. tritici

TABLE 2. Infection types on 103 wheat varieties to four Blumeria graminis f. sp. tritici isolates (HY5, MX20, HX4, and CCQ15) at the seedling stage and flanking markers of PmTx45 validation in 86 wheat varieties

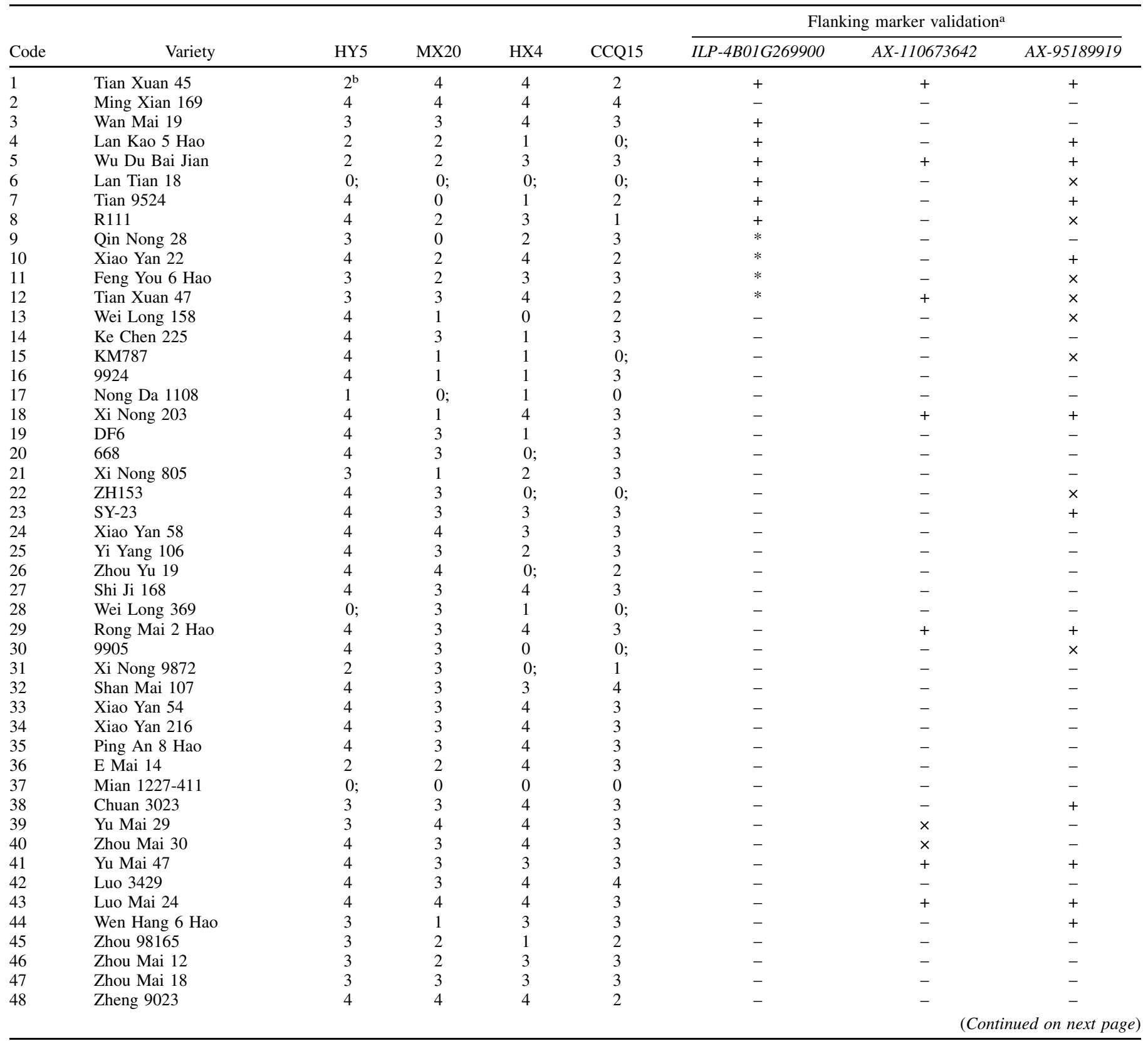

a The plus sign (+) indicates that the genotype of the test variety was the same as Tian Xuan 45, the dash (-) indicates that the genotype of test variety was different from Tian Xuan 45 , the asterisk $\left(^{*}\right)$ means the variety was not used to test, and the multiplication symbol $(x)$ indicates that Kompetitive allele-specific polymerase chain reaction test genotyping failed.

b Infection types were scored 14 days after inoculation using the following ratings: 0 , no visible spots; 0;, necrotic reactions or dead spots could be seen on the leaves, but the leaves had no sporulation; 1, a bit of the colony could be seen on the leaves but the diameter of each was less than $1 \mathrm{~mm}$, and sparse aerial hypha and little sporulation also could be seen on the leaves; 2 , the diameter of the colonies was less than $1 \mathrm{~mm}$ but moderate aerial hypha and sporulation could be seen on the leaves; 3 , thick aerial hypha and abundant sporulation were observed, and the diameter of the colonies was greater than $1 \mathrm{~mm}$, but the lesion was not continuous; and 4, thick aerial hypha and abundant sporulation were present, and lesions were continuous. 
isolates to test the seedling resistance of Tian Xuan 45 and the 102 other commercial wheat varieties, since they contained different virulence genes among each other and were the commonly used $B$. graminis $\mathrm{f}$. sp. tritici isolates for resistance genetic analysis in China (Ma et al. 2014; Table 1). HY5, MX20, HX4, and CCQ15 were collected from Heyang County $\left(35^{\circ} 14^{\prime} \mathrm{N}, 110^{\circ} 08^{\prime} \mathrm{E}\right)$, Meixian County $\left(34^{\circ} 16^{\prime} \mathrm{N}, 107^{\circ} 44^{\prime} \mathrm{E}\right)$, Huazhou District $\left(34^{\circ} 29^{\prime} \mathrm{N}, 109^{\circ} 46^{\prime} \mathrm{E}\right)$, and Chencang District $\left(34^{\circ} 21^{\prime} \mathrm{N}, 107^{\circ} 22^{\prime} \mathrm{E}\right)$, respectively, in the wheat growing area of Shaanxi Province. The B. graminis f. sp. tritici isolate HY5 was used to analyze the genetic resistance of Tian Xuan 45 because it was virulent on more varieties than the other three isolates (Table 2). Seedling tests of Tian Xuan 45, the 102 commercial wheat varieties, and the $\mathrm{F}_{1}$ and $\mathrm{F}_{2}$ populations of Ming Xian 169/Tian Xuan 45 were performed using the in vitro leaf segment method described above. $\mathrm{F}_{3}$ populations were inoculated directly in seedlings. Fifteen seeds of each $\mathrm{F}_{3}$ family line were sown in individual pots placed in a greenhouse. When the seedlings of $F_{3}$ populations had grown to the two-leaf stage, conidiospores of the HY5 B. graminis f. sp. tritici isolate were directly inoculated to the leaves by shaking. After 14 days, the infection types on each plant were recorded according to the above criteria (rating from 0 to 4 ). The observed segregation ratio of plants resistant and susceptible to

TABLE 2. (Continued from previous page)

\begin{tabular}{|c|c|c|c|c|c|c|c|c|}
\hline \multirow[b]{2}{*}{ Code } & \multirow[b]{2}{*}{ Variety } & \multirow[b]{2}{*}{ HY5 } & \multirow[b]{2}{*}{ MX20 } & \multirow[b]{2}{*}{ HX4 } & \multirow[b]{2}{*}{ CCQ15 } & \multicolumn{3}{|c|}{ Flanking marker validation ${ }^{\mathrm{a}}$} \\
\hline & & & & & & $I L P-4 B 01 G 269900$ & $A X-110673642$ & $A X-95189919$ \\
\hline 49 & Yan Zhan 4110 & 3 & 4 & 0 & 1 & - & + & + \\
\hline 50 & Zhong Liang 16 & 2 & 4 & 2 & 2 & - & + & + \\
\hline 51 & Zhong Liang 9589 & 0 & 2 & 0 & 2 & - & - & + \\
\hline 52 & Zhong Liang 9483 & 2 & 3 & 3 & 2 & - & - & + \\
\hline 53 & Tian 98101 & 3 & 3 & 3 & 3 & - & - & + \\
\hline 54 & Lan Tian 1 Hao & 4 & 3 & 3 & 4 & - & - & + \\
\hline 55 & Zhong Liang 96289 & 0 & 0 & 0 & 0 & - & - & - \\
\hline 56 & Lan Tian $10 \mathrm{Hao}$ & 3 & 2 & 3 & 3 & - & - & - \\
\hline 57 & Tian Xuan 43 & 2 & 3 & 0 & 3 & - & - & + \\
\hline 58 & Zhong Liang 969 & 2 & 4 & 3 & 3 & - & - & - \\
\hline 59 & Bai Da Tou & 3 & 2 & 3 & 3 & - & - & $x$ \\
\hline 60 & N.S & 0 & 0 & 2 & 0 & - & + & + \\
\hline 61 & Zhong Liang 22 & 3 & 3 & 3 & 3 & - & + & + \\
\hline 62 & SW8588 & 2 & 3 & 3 & 3 & - & - & - \\
\hline 63 & Tian Xuan 46 & 3 & 3 & 3 & 2 & - & - & - \\
\hline 64 & 200461 & 1 & 0 & 1 & 0 & - & + & + \\
\hline 65 & Tian 94-3 & 4 & 2 & 2 & 2 & - & - & + \\
\hline 66 & 92R-178 & 0 & 0 & 0 & 0 & - & - & - \\
\hline 67 & Zhong Liang 93447 & 4 & 4 & 4 & 2 & - & + & + \\
\hline 68 & Yan 9201 & 4 & 2 & 4 & 2 & - & + & + \\
\hline 69 & Zhong Liang 93444 & 4 & 4 & 4 & 2 & - & - & $x$ \\
\hline 70 & R39-26-10-1 & 4 & 4 & 4 & 3 & - & - & - \\
\hline 71 & R39-40-22-1 & 4 & 4 & 4 & 3 & - & - & - \\
\hline 72 & $\mathrm{Ta} 04-50(90 \mathrm{x})-1-1$ & 0 & 0 & 0 & 0 & - & - & - \\
\hline 73 & $\mathrm{Ta} 04-28(09 \mathrm{x})-241$ & 3 & 3 & 4 & 1 & - & - & - \\
\hline 74 & $\mathrm{Ta} 01-52-1-2-2-1$ & 0 & 0 & 1 & 0 & - & - & - \\
\hline 75 & Gui Nong 22 & 4 & 4 & 3 & 2 & - & - & - \\
\hline 76 & Gui Nong 775 & 0 & 0 & 0 & 0 & - & - & $x$ \\
\hline 77 & Xi Ke 01015 & 4 & 4 & 3 & 0 & - & - & $x$ \\
\hline 78 & San Shu Mai 3 Hao & 0 & 0 & 0 & 0 & - & - & $\times$ \\
\hline 79 & Moro & 4 & 3 & 4 & 2 & - & - & - \\
\hline 80 & Gaby & 4 & 4 & 4 & 3 & - & + & + \\
\hline 81 & Lu Mai 23 & 4 & 4 & 4 & 3 & - & - & - \\
\hline 82 & Yan Nong 15 Hao & 4 & 4 & 4 & 2 & - & - & - \\
\hline 83 & Lin Mai 77 & 4 & 4 & 4 & 2 & - & - & - \\
\hline 84 & Ming Tian 07112 & 4 & 3 & 2 & 3 & - & - & - \\
\hline 85 & Zhong 4 & 4 & 3 & 3 & 2 & - & - & $x$ \\
\hline 86 & Hui Xian Hong & 4 & 4 & 4 & 4 & - & + & + \\
\hline 87 & $03-9-2$ & 4 & 3 & 0 & 2 & $*$ & $*$ & $*$ \\
\hline 88 & S03-8 & 4 & 1 & 3 & 3 & $*$ & $*$ & $*$ \\
\hline 89 & XM68 & 4 & 0 & 0 & 2 & $*$ & $*$ & $*$ \\
\hline 90 & X831 & 4 & 1 & 3 & 4 & $*$ & $*$ & $*$ \\
\hline 91 & Hong Di 168 & 4 & 1 & 0 & 0 & $*$ & $*$ & $*$ \\
\hline 92 & Xi Nong 585 & 4 & 3 & 3 & 3 & $*$ & $*$ & $*$ \\
\hline 93 & Lu Feng Shuang Da 1 Hao & 3 & 3 & 4 & 3 & $*$ & $*$ & $*$ \\
\hline 94 & $\mathrm{H} 231$ & 3 & 2 & 2 & 0 & $*$ & $*$ & $*$ \\
\hline 95 & Ke Nong 1006 & 4 & 3 & 4 & 2 & $*$ & $*$ & $*$ \\
\hline 96 & Zhong Mai 629 & 3 & 2 & 1 & 0 & $*$ & $*$ & $*$ \\
\hline 97 & Long Yuan 935 & 3 & 3 & 3 & 3 & $*$ & $*$ & $*$ \\
\hline 98 & $01-3570$ & 3 & 1 & 2 & 2 & $*$ & $*$ & $*$ \\
\hline 99 & $\mathrm{Ta} 04-44-28$ & 0 & 2 & 0 & 0 & $*$ & $*$ & $*$ \\
\hline 100 & Zhong Guo Chun & 4 & 4 & 4 & 2 & $*$ & $*$ & $*$ \\
\hline 101 & Jin Mai 47 & 4 & 4 & 4 & 3 & $*$ & $*$ & $*$ \\
\hline 102 & Zhong Liang 27 & 4 & 4 & 0 & 2 & $*$ & $*$ & $*$ \\
\hline 103 & 88375 & 4 & 3 & 4 & 3 & $*$ & $*$ & $*$ \\
\hline
\end{tabular}


powdery mildew and the expected ratio were tested for fitness of the predicted inheritance model using the $\chi^{2}$ test to determine the number of resistance genes.

Microarray-based BSA. The DNA of 15 resistant and 15 susceptible $\mathrm{F}_{2}$ individuals was extracted from fresh seedling leaves using the cetyltrimethylammonium bromide (CTAB) method as modified by Yan et al. (2003) to construct resistance bulk and susceptible bulk. The bulks and parents were genotyped with 660K SNP arrays (Jia and Zhao 2016) from CapitalBio Corporation. The Axiom Analysis Suite (Thermo Fisher Scientific) was used for SNP genotype calling and clustering. To ensure that the relevant area was not deleted, all genotyping results were used in the later analysis. After comparing the genotyping results of the four samples of Tian Xuan 45, Ming Xian 169, resistance bulk, and susceptible bulk, the polymorphic SNPs that differed between resistant and susceptible parents and also had the same difference in bulks were selected. To determine the location of each SNP on wheat chromosome, we used the Basic Local Alignment Search Tool (BLAST) v2.5.0+ (https://blast.ncbi.nlm. nih.gov/) to search the International Wheat Genome Sequencing Consortium (IWGSC) Wheat Reference Genome RefSeq v1.0 database (2014; https://urgi.versailles.inra.fr and http://www. wheatgenome.org). A total of 630,517 SNPs from the $660 \mathrm{~K}$ chip were used to BLAST search the reference database, with an "evalue" setting of 0.00001 . The BLAST results only retained the data where the "percent identity" was 100 on each chromosome, and duplicates were eliminated so that an SNP sequence could appear on each chromosome once at most but could still appear on different chromosomes. Then we counted three datasets. The first dataset was the number of all of the SNPs in $660 \mathrm{~K}$ chips contained per $1 \mathrm{Mbp}$ per chromosome by the above method. The second dataset was the number of polymorphic SNPs selected by BSA contained per $1 \mathrm{Mbp}$ per chromosome. The third dataset was the relative frequency distribution of polymorphic SNPs, measured by calculating the ratio of the polymorphic number of SNPs to the number of all of the SNPs in $660 \mathrm{~K}$ chips per $1 \mathrm{Mbp}$ per chromosome. This ratio is expressed in $P$ values. Circos 0.69-6 software (http://circos.ca/ software/download/) was used to draw plots to illustrate the three datasets. Additionally, the Geneview Python package (https:// github.com/ShujiaHuang/geneview\#geneview-a-python-packagefor-genomics-data-visualization) was used to draw a Manhattan plot to show the third dataset. Through analyzing these results, we initially determined the possible regions of the resistance gene loci on wheat chromosomes.

Kompetitive allele-specific PCR marker assays and genotyping. The polymorphic SNP markers in the target region were randomly selected to design Kompetitive allele-specific PCR (KASP) markers by PolyMarker (Ramirez-Gonzalez et al. 2015). Chromosome-specific KASP markers were used to genotype individual $F_{2}$ plants (Semagn et al. 2014). A 5- $\mu$ l KASP reaction

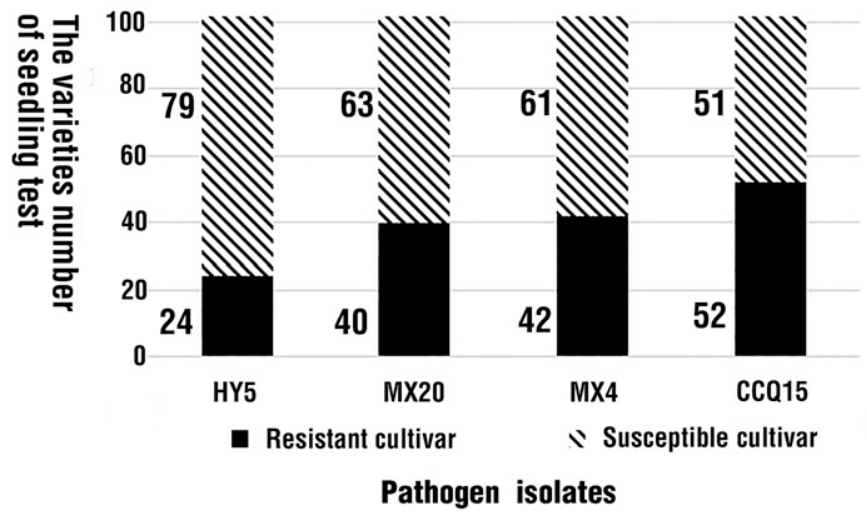

Fig. 1. The seedling test result of 103 varieties to Blumeria graminis f. sp. tritici isolates MX20, MX4, HY5, and CCQ15. mixture consisted of 50 to $100 \mathrm{ng}$ of wheat genomic DNA, $0.056 \mu \mathrm{l}$ of assay primer mix (12 $\mathrm{mM}$ of each allele-specific primer [6-carboxy$2^{\prime}, 4,4^{\prime}, 5^{\prime}, 7,7^{\prime}$-hexachlorofluorescein succinimidyl ester (HEX) and 6Fluorescein Phosphoramidite (FAM) primers] and $30 \mathrm{mM}$ of common primer), $2.5 \mu \mathrm{l}$ of $2 \times$ KASP v4.0 Master mix (LGC Genomics), and sterile deionized distilled water, which was used to complement the reaction system (He et al. 2014; Wu et al. 2017). The KASP assay was programmed for initial denaturation at $94^{\circ} \mathrm{C}$ for $15 \mathrm{~min}$, nine cycles of $94^{\circ} \mathrm{C}$ for $20 \mathrm{~s}$, and touchdown starting at $65^{\circ} \mathrm{C}$ (decreasing by $0.8^{\circ} \mathrm{C}$ per cycle) for $1 \mathrm{~min}$, followed by 30 to 40 cycles of amplification at $94^{\circ} \mathrm{C}$ for $20 \mathrm{~s}$ and at $57^{\circ} \mathrm{C}$ for $1 \mathrm{~min}$ (Wu et al. 2017). The KASP assay was done in an S1000 thermal cycler with a 384-well plate (Bio-Rad Laboratories).

Linkage map construction and candidate gene analysis. The genotypes of each marker and resistance gene locus for the $F_{2: 3}$ population were used to construct a linkage map with JoinMap 4.0 software (van Ooijen 2006). The grouping mode was set as the independent limit of detection (LOD), the mapping algorithm was set as regression mapping, the mapping function was set as a Kosambi function (Kosambi 1943), and the linkage LOD score was 5.0 as a threshold. Missing data were considered a blank value to participate in the analysis. Genotypic markers used to construct genetic linkage maps were tested using $\chi^{2}$ tests to exclude markers with distorted segregation $(P>0.001)$ (Wu et al. 2018). Mapchart v2.3 software (Voorrips 2002) was used to visualize the linkage map. In addition, we used more than 700 deletion-bin-known expressed sequence tag (EST) sequences, which were downloaded from the GrainGenes database (https://wheat.pw.usda.gov/) on the 4B chromosome to BLAST search the IWGSC RefSeq v1.0 database, to determine the deletion bins of the resistance gene. Based on the target region, the IWGSC RefSeq v1.0 annotation database (https://urgi.versailles.inra. $\mathrm{fr} /$ ) was used to analyze candidate genes.

Comparative genomics collinearity analysis and intron length polymorphism marker development. Based on the deletion bins of the resistance genes, we used wheat EST sequences to BLAST search the Brachypodium distachyon v1.0 DNA database and the Oryza sativa International Rice Genome Sequencing Project v1.0 DNA database from the Joint Genome Institute Genome Portal (https://genome.jgi.doe.gov/) to analyze the collinearity between $B$. distachyon and $O$. sativa. Subsequently, BLAST was used for the candidate genes on the National Center for Biotechnology Information website to compare them with the $B$. distachyon and $O$. sativa genome database. Combined with the IWGSC RefSeq v1.0 annotation database, the exons and introns of candidate genes were identified, and we designed 85 pairs of intron length polymorphism (ILP) markers with Primer Premier 5 software (http://www.premierbiosoft.com/primerdesign/) to find more markers linked to the target genes (Choi et al. 2007; Wei et al. 2005; Yang et al. 2007). The 50- $\mu$ l reaction mixtures consisted of $25 \mu \mathrm{l}$ of $2 \times$ Es Taq MasterMix (CoWin Biosciences), $2 \mu 1$ of each of

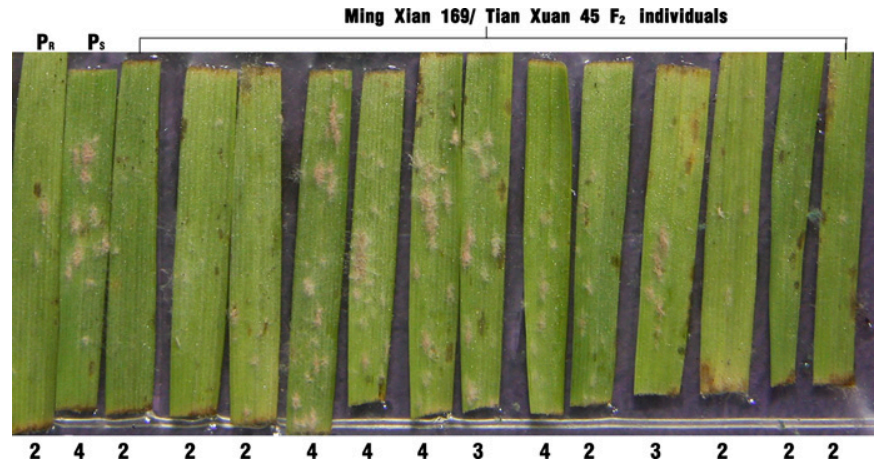

Fig. 2. Infection types (ITs) of the Ming Xian 169/Tian Xuan 45 cross population to Blumeria graminis f. sp. tritici isolate HY5 at the seedling stage. IT 2 was regarded as resistant, and ITs 3 and 4 as susceptible. $P_{R}=$ Tian Xuan 45, and $\mathrm{P}_{\mathrm{S}}=$ Ming Xian 169 . 
the forward and reverse primers $(5 \mu \mathrm{M}), 5 \mu \mathrm{l}$ of template DNA $(50 \mathrm{ng} / \mu \mathrm{l})$, and sterile deionized distilled water, which was used to complement the reaction system. PCR amplifications for ILP marker analysis were performed on an S1000 thermal cycler (BioRad Laboratories) and were programmed as follows: at $94^{\circ} \mathrm{C}$ for $4 \mathrm{~min}$ for initial denaturation; then 14 decreasing cycles, each consisting of $94^{\circ} \mathrm{C}$ for $30 \mathrm{~s}, 55^{\circ} \mathrm{C}$ (decreasing by $0.8^{\circ} \mathrm{C}$ per cycle) for $1 \mathrm{~min}$, and $72^{\circ} \mathrm{C}$ for $1 \mathrm{~min}$; and 19 cycles, each consisting of $94^{\circ} \mathrm{C}$ for $30 \mathrm{~s}, 50^{\circ} \mathrm{C}$ for $30 \mathrm{~s}$, and $72^{\circ} \mathrm{C}$ for $1 \mathrm{~min}$, followed by a final 10 min extension at $72^{\circ} \mathrm{C}$. A total of $6 \mu \mathrm{L}$ of PCR product was electrophoresed in $1 \%$ agarose gel with DuRed nucleic acid gel stain and visualized under ultraviolet light. All individual genotypes amplified by ILP primers were also used to construct the genetic map along with the previous markers using the methods described above.

Validation of markers flanking target resistance genes. A total of 86 wheat varieties that had been tested with HY5 at the seedling stage were used to verify the three closed markers linked to resistance genes. The methods of DNA genomic extraction and marker amplification were as described above.

\section{RESULTS}

Pathogen isolation and identification. Results of the evaluation of the powdery mildew response of HY5, MX20, HX4, and CCQ15 to 32 differential hosts and 103 commercial wheat varieties are shown in Tables 1 and 2 and Figure 1. These four isolates showed a virulence pattern different from the predominant isolates of China, harboring virulence to more than half of the varieties at the seedling stage. In those varieties, only $22.33 \%$ had resistance to HY5. Tian Xuan 45 had resistance to HY5 and CCQ15. The varieties that were resistant to two isolates accounted for $11.65 \%$ of all tested varieties. These data indicated that further study of the resistance in Tian Xuan 45 to HY5 has significant value to resistance breeding.

TABLE 3. Genetic analysis of resistance in Tian Xuan 45 to Blumeria graminis f. sp. tritici race HY5

\begin{tabular}{|c|c|c|c|c|c|c|c|}
\hline \multirow[b]{2}{*}{ Parent and population } & \multicolumn{3}{|c|}{ Observed number of plant lines ${ }^{a}$} & \multirow[b]{2}{*}{ Total } & \multirow[b]{2}{*}{ Expected ratio } & \multirow[b]{2}{*}{$\chi^{2}$} & \multirow[b]{2}{*}{$P$} \\
\hline & Resistant & Segregating & Susceptible & & & & \\
\hline Tian Xuan 45 & 17 & - & 0 & 17 & & & \\
\hline Ming Xian 169 & 0 & - & 17 & 17 & & & \\
\hline $\mathrm{F}_{1}$ & 0 & - & 15 & 15 & & & \\
\hline $\mathrm{F}_{2-1}$ & $24(\mathrm{IT}=2)$ & - & $\begin{array}{l}81(55[\mathrm{IT}=3] \\
+26[\mathrm{IT}=4])\end{array}$ & 105 & $1: 3$ & 0.2571 & 0.6121 \\
\hline $\mathrm{F}_{2: 3}$ & 18 & 54 & 29 & 101 & $1: 2: 1$ & 2.8811 & 0.2368 \\
\hline
\end{tabular}

a Dashes indicate that there is no phenotypic separation in the parent or population. IT = infection type.

A

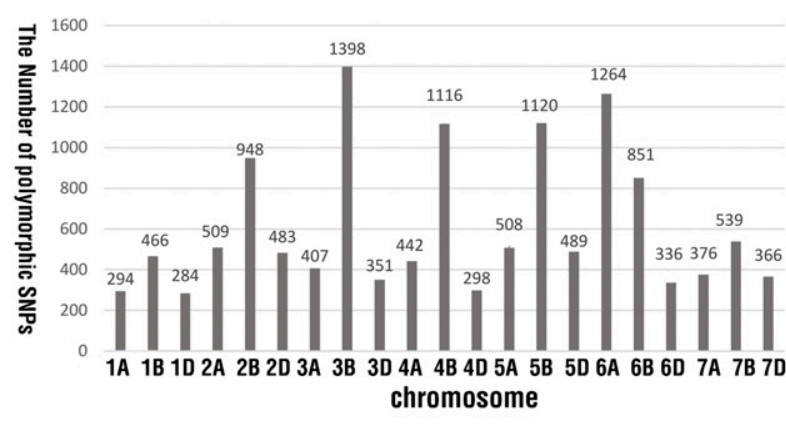

B

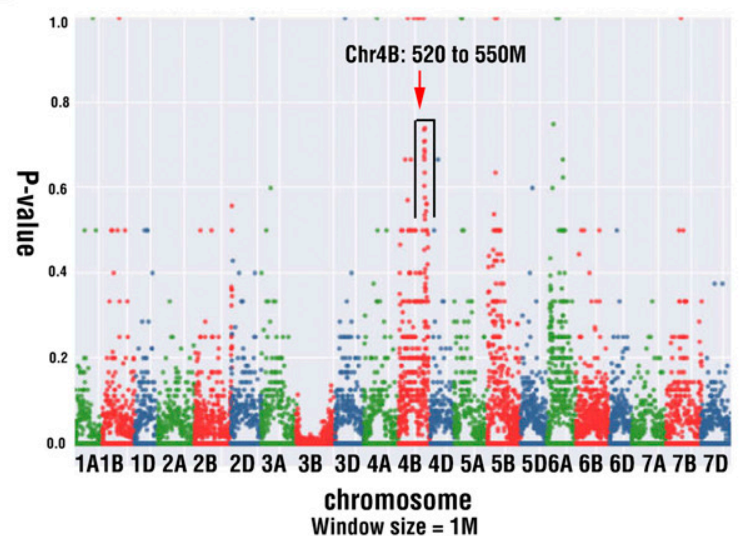

C

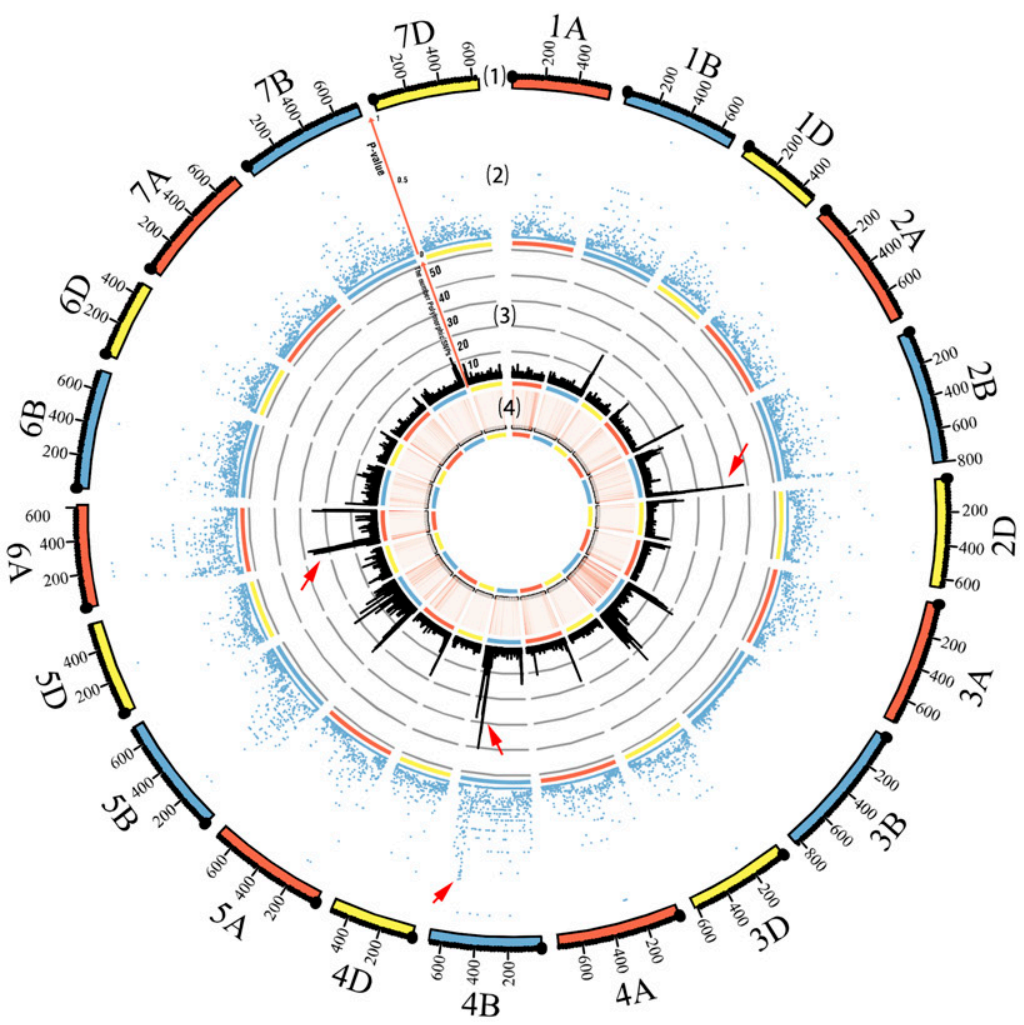

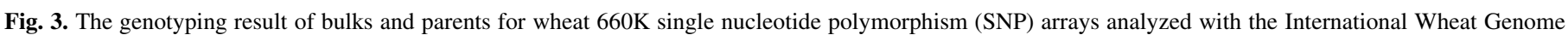

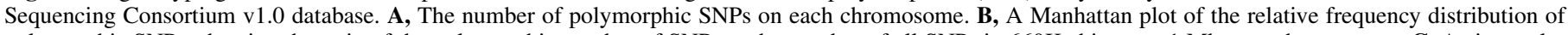

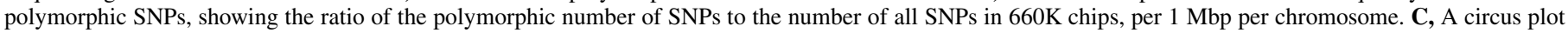

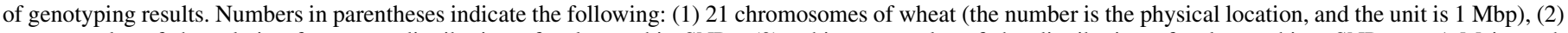

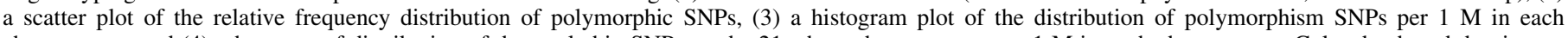

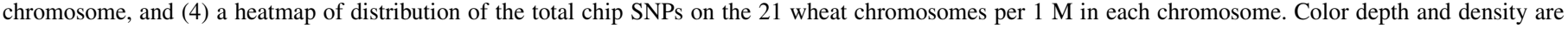
positively correlated. The arrow indicates where the target gene is initially located. 
Inheritance of powdery mildew resistance from Tian Xuan 45. The resistant parent Tian Xuan 45 displayed a moderately resistant infection type of 2 , whereas susceptible parent Ming Xian 169 showed a susceptible infection type of 4 . Fifteen $F_{1}$ plants from the Ming Xian 169/Tian Xuan 45 cross were susceptible and not the same as a susceptible parent. The infection type of $F_{1}$ plants was between 3 and 4 . The 105 plants of the $F_{2}$ population segregated as 24 resistant/81 susceptible, fitting the $1: 3$ ratio $\left(\chi^{2}=\right.$ $0.2571<3.84 ; P=0.5338)$. For this $\mathrm{F}_{2}$ population, no plants with an infection type of 0,0 ; , or 1 were found. The $F_{2}$ population segregated as 24:55:26 for infection types 2,3 , and 4, respectively,

A

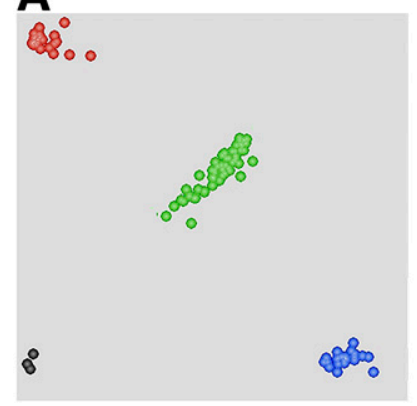

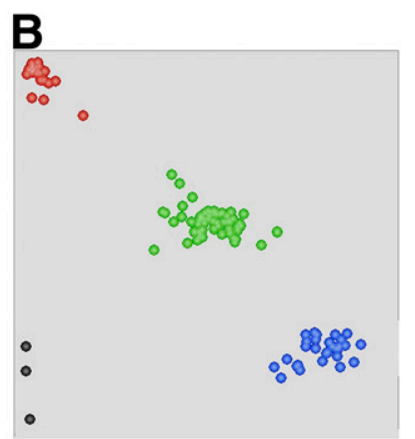

Fig. 4. Kompetitive allele-specific polymerase chain reaction assays showing clustering of the $F_{2}$ population of the Ming Xian 169/Tian Xuan 45 cross on scatter plots. Markers of A, $A X-110673642$ and B, $A X-95189919$ divided the population into three distinct clusters. The green cluster was composed of heterozygous individuals, whereas clusters near the axes were homozygous for either Ming Xian 169 (red) or Tian Xuan 45 (blue). Black dots represent the nontemplate control. fitting the $1: 2: 1$ ratio $\left(\chi^{2}=0.3143<5.99 ; P=0.8546\right)($ Fig. 2$)$. The $101 \mathrm{~F}_{2: 3}$ families (four plants had died during transplanting) were classified as 18 homozygous-resistant, 54 segregating, and 29 homozygous-susceptible types, respectively, fitting the 1:2:1 ratio $\left(\chi^{2}=2.8811<5.99 ; P=0.2368\right)$ (Table 3$)$. These results indicated that the resistant character of Tian Xuan 45 to HY5 was a single recessive locus. We tentatively designated this locus as PmTx45.

Microarray-based BSA initially determined the locus of the resistance gene. The genotyping results of the bulks and parents for the $660 \mathrm{~K} \mathrm{SNP}$ arrays analyzed with the IWGSC RefSeq v1.0 database are shown in Figure 3. Chromosomes 2B, 3B, 4B, 5B, $6 \mathrm{~A}$, and 6B had more polymorphic SNPs than other chromosomes, based on the distribution of the number of polymorphic SNPs per chromosome. For this result, we could not locate the resistance gene in chromosomes by only the enrichment of the polymorphic SNPs on the chromosome data (Fig. 3A). According to the results of the distribution of polymorphism SNPs per $1 \mathrm{Mbp}$ in each chromosome, we found that $2 \mathrm{~B}, 4 \mathrm{~B}$, and $6 \mathrm{~A}$ may have higher probability to be the chromosomes that contained PmTx45. 5B and 3B did not show a particularly high enrichment peak under this plot, because the chip had more on the loci of the two chromosomes (Cui et al. 2017; Fig. 3C). Figure 3B and C (2) use a Manhattan plot and a scatter plot to display a dataset on the relative frequency distribution of polymorphic SNPs, illustrating the ratio of the polymorphic number of SNPs to the number of all of the SNPs in 660K chips, per $1 \mathrm{Mbp}$ per chromosome. There was a significant continuous rising distribution at the end of chromosome 4BL in those two plots, so we initially located the resistance gene in the range of 520 to $550 \mathrm{Mbp}$ of 4BL.

Identification of SNP markers linked to PmTx45. We designed 30 pairs of KASP primers selected from 30 chromosomespecific SNPs in the interval of 520 to $550 \mathrm{Mbp}$ on chromosome

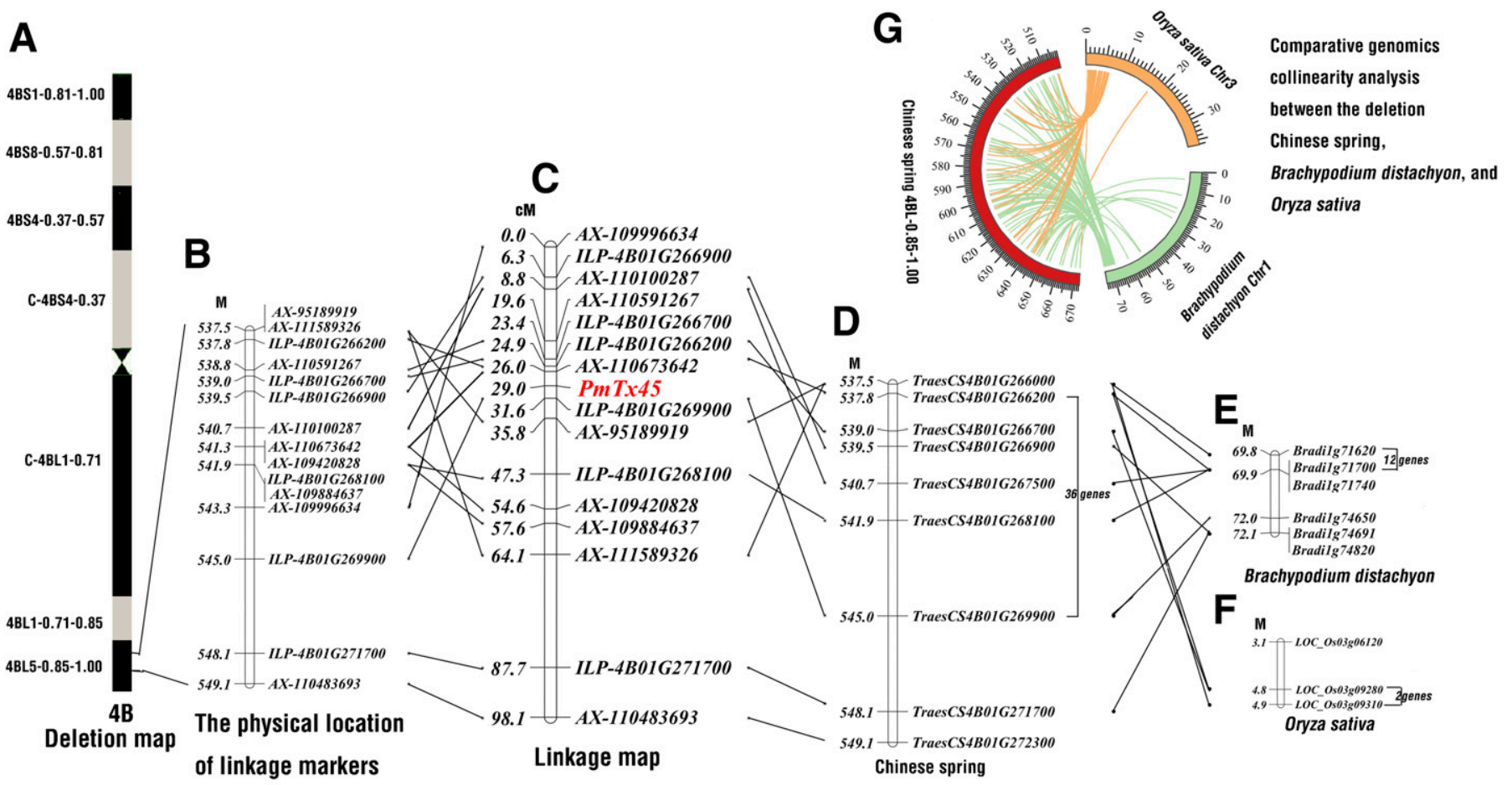

Markers associated candidate genes

Fig. 5. The linkage map of PmTx45 and marker-related candidate genes. A, The deletion map of wheat chromosome 4B (http://wheat.pw.usda.gov/NSF). B, The physical location of linkage markers. The position of markers in chromosome 4B of the International Wheat Genome Sequencing Consortium RefSeq database is shown on the left. The numeric unit is $1 \mathrm{Mbp}$. C, The linkage map of PmTx45. Map distances in centimorgans are shown on the left. Candidate genes associated with markers in D, Chinese Spring, E, Brachypodium distachyon, and F, Oryza sativa, respectively. G, Comparative genomics collinearity analysis between Chinese Spring, B. distachyon, and $O$. sativa. 
4BL for genotyping. Because the ratio of $F_{2}$ individuals with infection types of 2,3 , and 4 fit the $1: 2: 1$ ratio, a dataset was designed with an infection type of 2 as the resistance phenotype, an infection type of 3 as the heterozygous phenotype, and an infection type of 4 as the susceptible phenotype for linkage analysis, using JoinMap 4.0 with the genotypes from the KASP assay. The linkage map showed that nine markers of $A X-109996634, A X-110100287$, $A X-110591267, A X-220673642, A X-95189919, A X-109420828$,

TABLE 4. Numbers of $F_{2}$ populations from the Ming Xian 169/Tian Xuan 45 cross with homozygous Tian Xuan 45 (A) and Ming Xian 169 (B) and heterozygous (H) alleles of ILP or KASP markers linked to powdery mildew resistance genes PmTx45 and probability values of $\chi^{2}$ tests for goodness of fit to a single gene locus ${ }^{\mathrm{a}}$

\begin{tabular}{|c|c|c|c|c|c|c|c|c|c|c|c|}
\hline \multirow[b]{3}{*}{ Marker } & \multirow{2}{*}{\multicolumn{3}{|c|}{$\begin{array}{c}\text { Resistant plants }(n) \\
\text { IT }=2\end{array}$}} & \multicolumn{6}{|c|}{ Susceptible plants $(n)$} & \multirow[b]{3}{*}{$\chi^{2}$ for $(\mathrm{A}: \mathrm{H}+\mathrm{B})=1: 3$} & \multirow[b]{3}{*}{$P^{\mathrm{b}}$} \\
\hline & & & & \multicolumn{3}{|c|}{$\mathrm{IT}=3$} & \multicolumn{3}{|c|}{$\mathrm{IT}=4$} & & \\
\hline & $\mathrm{A}$ & $\mathrm{H}$ & $\mathrm{B}$ & $\mathrm{A}$ & $\mathrm{H}$ & $\mathrm{B}$ & A & $\mathrm{H}$ & $\mathrm{B}$ & & \\
\hline ILP-4B01G266900 & 22 & - & 2 & 5 & - & 50 & 4 & - & 22 & 1.15 & 0.28 \\
\hline$A X-110100287$ & 19 & 5 & 0 & 2 & 45 & 8 & 5 & 2 & 19 & 0.03 & 0.96 \\
\hline$A X-110591267$ & 24 & 0 & 0 & 3 & 51 & 1 & 2 & 6 & 18 & 0.38 & 0.54 \\
\hline ILP-4B01G266700 & 23 & 1 & 0 & 2 & 52 & 1 & 0 & 9 & 17 & 0.08 & 0.78 \\
\hline$I L P-4 B 01 G 269900$ & 22 & - & 2 & 1 & - & 54 & 0 & - & 26 & 0.54 & 0.46 \\
\hline$A X-95189919$ & 18 & - & 6 & 1 & 50 & 4 & 0 & - & 26 & 2.67 & 0.1 \\
\hline$A X-109420828$ & 12 & 9 & 3 & 4 & 38 & 13 & 1 & 3 & 22 & 4.35 & 0.04 \\
\hline$I L P-4 B 01 G 268100$ & 14 & - & 10 & 5 & - & 50 & 0 & - & 26 & 2.67 & 0.1 \\
\hline$A X-109884637^{c}$ & 15 & 5 & 3 & 4 & 30 & 21 & 0 & 5 & 21 & 2.51 & 0.11 \\
\hline$A X-111589326$ & 11 & 9 & 4 & 1 & 39 & 15 & 1 & 8 & 17 & 8.92 & $*$ \\
\hline$I L P-4 B 01 G 271700$ & 14 & 2 & 8 & 3 & 10 & 42 & 2 & 2 & 22 & 2.67 & 0.1 \\
\hline
\end{tabular}

a Dashes indicate that the marker was a dominant marker, and heterozygous alleles cannot be distinguished from homozygous alleles. A = resistant parent allele, $\mathrm{B}=$ susceptible parent allele, $\mathrm{H}=$ heterozygous allele, ILP = intron length polymorphism, KASP = Kompetitive allele-specific polymerase chain reaction, and IT $=$ infection type.

b The asterisk indicates that although $P<0.05$, these markers and $P m T x 45$ are in the same group by calculation.

c The genotyping result of a resistance plant for marker $A X-109884637$ was missing.

TABLE 5. Information on the marker positions in wheat chromosome 4B based on the reference genome sequence of the International Wheat Genome Sequencing Consortium RefSeq database

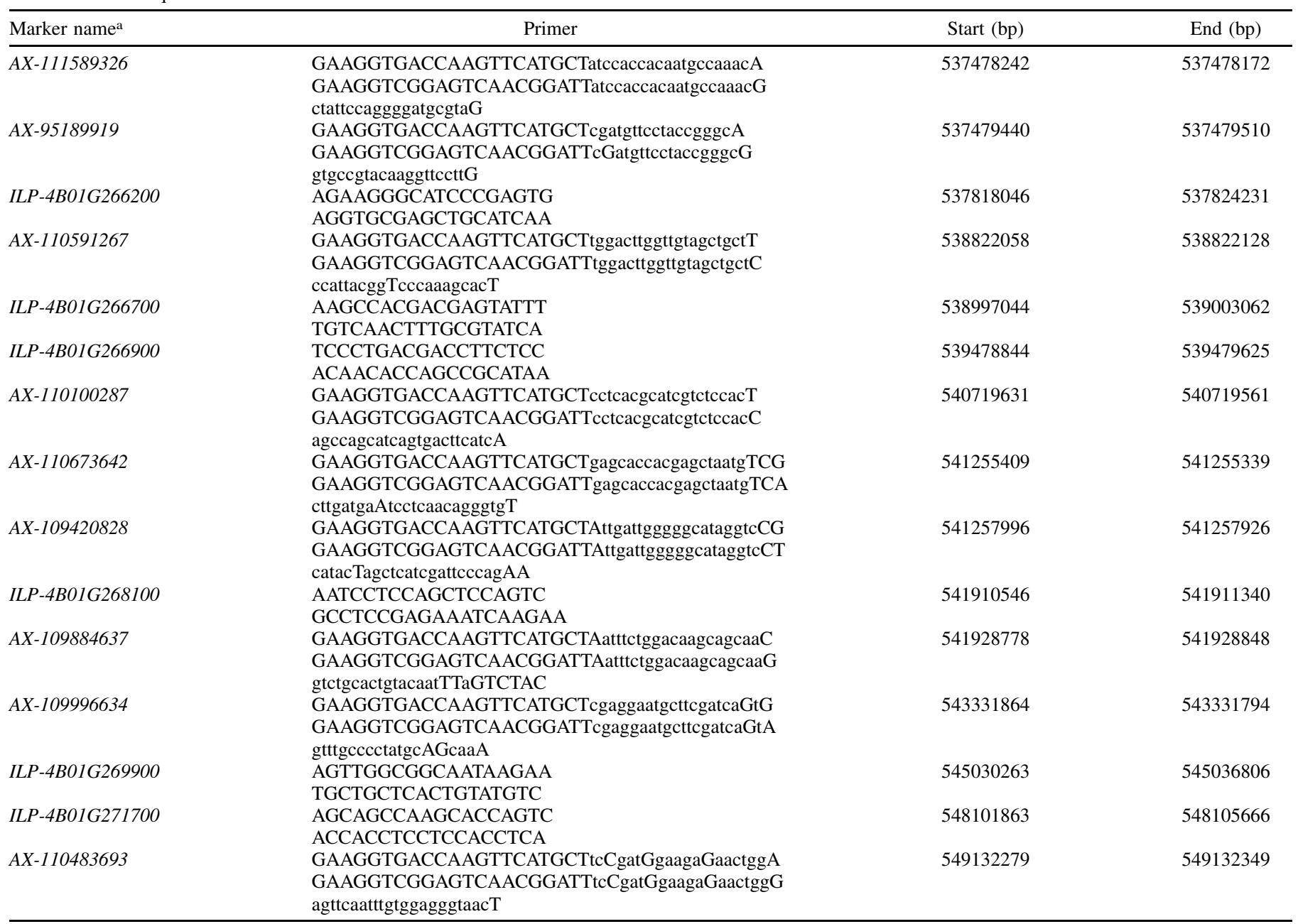

${ }^{a}$ ILP $=$ intron length polymorphism. 
$A X-109884637, A X-111589326$, and $A X-110483693$ and the resistance gene locus in Tian Xuan 45 had stringently linked, with an LOD score of 5.0 (Fig. 4). This result indicated that these nine markers were linked to PmTx45, spanning a genetic distance of 98.1 $\mathrm{cM}$. The original sequences of the 10 markers were used to BLAST search the IWGSC RefSeq v1.0 database to locate their position, and PmTx45 was more accurately located in the 537.48 to $549.13 \mathrm{M}$ on chromosome 4BL. More than 700 EST sequences on the 4B chromosome were used to BLAST search the IWGSC RefSeq v1.0 database to determine the physical position of their deletion bins. The results showed that the ESTs of deletion bin 4BL5-0.86-1.00 were focused on 520 to $570 \mathrm{M}$. Because this range contained the resistance locus of PmTx45, we deduced that PmTx45 might be located at 4BL5-0.86-1.00 (Fig. 5A and B).

Development and identification of ILP markers linked to PmTx45. Collinearity analysis showed that there was collinearity between 4BL5-0.86-1.00 of cultivar Chinese Spring, 68 to $75 \mathrm{M}$ of chr1 of $B$. distachyon, and 0 to $6 \mathrm{M}$ of chr 3 of $O$. sativa. A total of 200 ILP primers were designed from all 70 genes in the possible range of PmTx45 in the IWGSC RefSeq v1.0 annotation database. Thirty disease-related genes that contained a diseaserelated conserved motif were selected from the collinearity range of $B$. distachyon, and 32 disease-related genes were selected from the collinearity range of $O$. sativa. After amplification, the ILP primers derived from $B$. distachyon and $O$. sativa showed multiple bands in agarose gel, and none of these markers had specific bands related to the resistance gene locus. These markers were not used for linkage analysis. The ILP primers derived from wheat genes produced robust bands, and several primers had polymorphism between the bulks and the parents. Six of these markers ILP-4B01G266700, ILP-4B01G269900, ILP-4B01G271700, ILP-4B01G266200, ILP4B01G268100, and ILP-4B01G266900 were linked to PmTx45 (Fig. 5).

Linkage map construction and candidate gene analysis. A linkage map constructed with the identified KASP and ILP markers is displayed in Figure 5. According to the map, the two flanking markers linked to PmTx45 were $A X-110673642$ and ILP$4 B 01 G 269900$, with genetic distances from the gene of 3.0 and 2.6 cM, respectively (Fig. 5C; Table 4). By comparing the genetic map and the physical map (Fig. 5B; Table 5), the order of the markers on the two maps was inconsistent. This out-of-order situation may be attributable to the different genetic background.

Table 6 and Figure 5D, E, and F illustrate the associated linkage markers of the candidate genes. The sequence of marker $A X$ 110673642 did not hit any genes in the IWGSC RefSeq v1.0 database. Thus, ILP-4B01G266200 and ILP-4B01G269900 were used to locate genes in TraesCS4B01G266200 to TraesCS4B01G269900. There were 36 genes between the two markers. $A X-95189919$ and $A X-110100287$, which hit Bradi1g71620 and Bradi1g71700, were the closest flanking markers that could hit $B$. distachyon genes. There were 12 genes between Bradi1g71620 and Bradi1g71700. AX-95189919 and ILP-4B01G266700, which hit LOC_Os03g09310 and LOC_Os03g09280, were the closest flanking markers that could hit $O$. sativa genes. Only two genes between LOC_ Os03g09280 and LOC_Os03g09310. Those 36 genes from Chinese Spring, 12 genes from $B$. distachyon, 2 genes from $O$. sativa (Supplementary Table S1), and 18 markers associated with the resistance gene locus (Table 6) were used to develop markers in the future experiments.

Flanking marker validation. ILP-4B01G269900, $A X$ 110673642 , and $A X-95189919$ were used to detect the presence

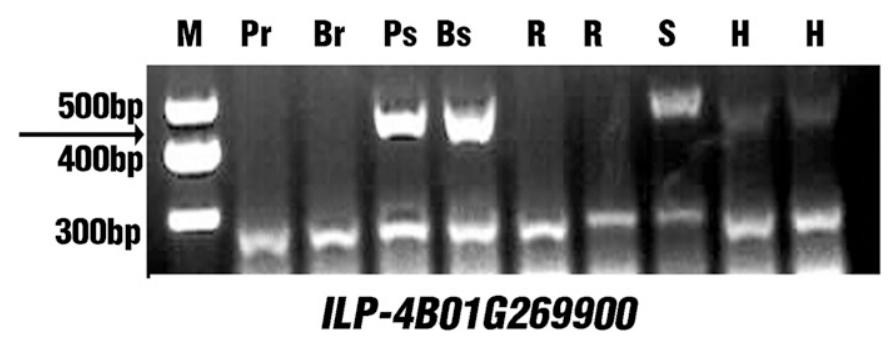

Fig. 6. Polymerase chain reaction profiles of intron length polymorphism (ILP) marker $I L P-4 B 01 G 269900$ in partial $\mathrm{F}_{2}$ plants from the cross of Ming Xian 169/Tian Xuan 45. Arrows indicate specific bands. $M=$ DNA marker, $\mathrm{P}_{\mathrm{r}}=$ Tian Xuan $45, \mathrm{Br}=$ resistant bulk, $\mathrm{P}_{\mathrm{s}}=$ Ming Xian $169, \mathrm{Bs}=$ susceptible bulk, $\mathrm{R}=$ resistant plant, $\mathrm{S}=$ susceptible plant, and $\mathrm{H}=$ heterozygous plant.

TABLE 6. The associated candidate genes of the markers

\begin{tabular}{|c|c|c|c|c|c|c|}
\hline \multirow[b]{2}{*}{ Marker } & \multicolumn{6}{|c|}{ Associated candidate gene ${ }^{\mathrm{a}}$} \\
\hline & Chinese Spring & Annotations & Oryza sativa & Annotations & $\begin{array}{c}\text { Brachypodium } \\
\text { distachyon }\end{array}$ & Annotations \\
\hline $\begin{array}{l}A X-111589326 \\
A X-95189919\end{array}$ & TraesCS4B01G266000 & Protein FRIGIDA & LOC_Os03g09310 & FRIGIDA-like 1 & Bradi1g71620 & FRIGIDA-like protein \\
\hline$A X-110100287$ & TraesCS4B01G267500 & $\begin{array}{l}\text { NADH dehydrogenase } \\
\text { [ubiquinone] } 1 \text { alpha } \\
\text { subcomplex subunit } 13\end{array}$ & - & - & Bradi1g71700 & $\begin{array}{l}\text { GRIM-19 protein, } \\
\text { NADH dehydrogenase } \\
1 \text { alpha subcomplex } \\
\text { subunit } 13 \text {, putative, } \\
\text { expressed }\end{array}$ \\
\hline$A X-110483693$ & TraesCS4B01G272300 & $\begin{array}{l}\text { Mid1-complementing } \\
\text { activity } 1 \text {, PLAC } 8 \\
\text { family }\end{array}$ & LOC_Os03g06120 & PLAC8 family protein & Bradi1g74650 & PLAC8 family protein \\
\hline ILP-4B01G266700 & TraesCS4B01G266700 & $\begin{array}{l}\text { GRAS transcription } \\
\text { factor }\end{array}$ & LOC_Os03g09280 & Scarecrow-like 5 & - & - \\
\hline ILP-4B01G266900 & TraesCS4B01G266900 & F-box family protein & - & - & - & - \\
\hline$I L P-4 B 01 G 271700$ & TraesCS4B01G271700 & F-box family protein & - & - & Bradi1g74691 & $\begin{array}{l}\text { F-box/RNI-like } \\
\text { superfamily protein }\end{array}$ \\
\hline ILP-4B01G269900 & TraesCS4B01G269900 & RNA-binding protein & - & - & Bradi1g74820 & $\begin{array}{l}\text { Splicing factor, CC1- } \\
\text { like, transposon } \\
\text { protein, putative, } \\
\text { CACTA, En/Spm } \\
\text { subclass, expressed }\end{array}$ \\
\hline
\end{tabular}

a Dashes indicate that the mark did not hit any genes in the corresponding species database. NADH = reduced form of nicotinamide-adenine dinucleotide, and ILP = intron length polymorphism. 
A

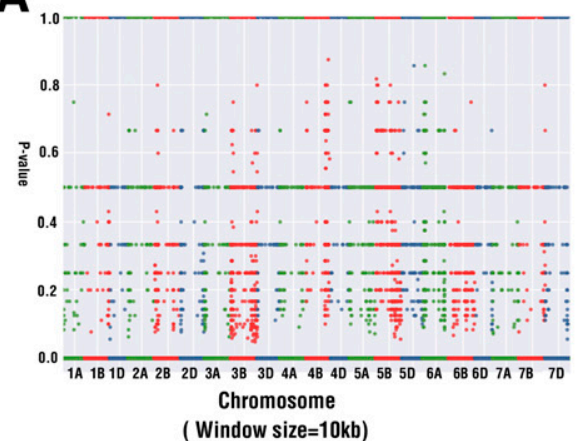

B

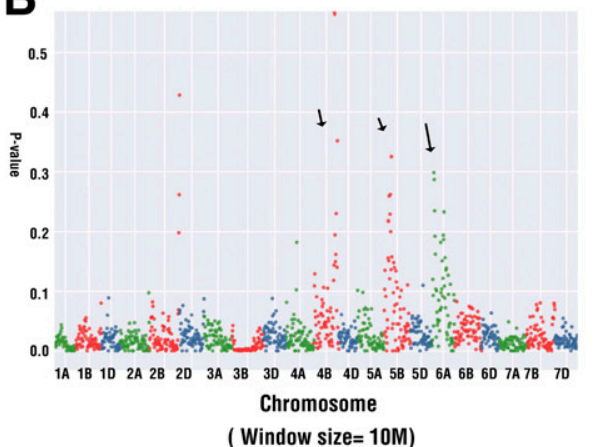

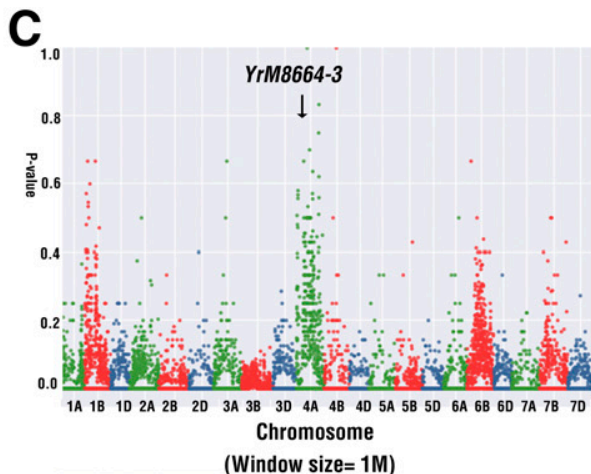

(Window size $=1 \mathrm{M}$ )

Fig. 7. Three Manhattan plots show the relative frequency distribution of polymorphic single nucleotide polymorphisms (SNPs) from microarray-based bulked segregant analysis in the $\mathrm{F}_{2}$ population of the Ming Xian 169/Tian Xuan 45 cross for the window screen sizes A, $10 \mathrm{~kb}$ and $\mathbf{B}, 10 \mathrm{M}$, respectively, and $\mathbf{C}$, the relative frequency distribution of polymorphic SNPs of a resistance gene YrM8664-3 from an $\mathrm{F}_{2}$ population of the Ming Xian 169/M8664-3 cross.

of PmTx45 in 86 wheat varieties that had been tested at the seedling stage with HY5 (Table 2). The results suggested that only variety Wu Du Bai Jian was resistant to HY5 and had those the three markers consistent with the genotype of Tian Xuan 45. Consequently, Wu Du Bai Jian may contain PmTx45. Tian Xuan 45 is resistant to all four isolates but $\mathrm{Wu}$ Du Bai Jian is only resistant to the two of them, because Tian Xuan 45 and Wu Du Bai Jian may contain other different disease resistance genes. Tian Xuan 45 had a null allele of dominant marker ILP-4B01G269900 (Fig. 6), and only six varieties had the same genotype. Combined with the detection results of $A X-110673642$, it was proven that the presence of $P m T x 45$ in the wheat varieties was rare, and the verification of these markers was effective.

\section{DISCUSSION}

Microarray-based BSA with the relative frequency distribution of polymorphic SNPs. In this study, we first used general analysis of the polymorphic SNP site-enrichment method to initially localize the target gene. However, because the difference between several chromosomes was not clear, we used the method of relative frequency distribution analysis of polymorphic SNPs to determine the specific location of the target gene. For this dataset, a Manhattan plot can be more intuitive and compact than a scatter plot to show this difference. This method is a variant of general SNP analysis of enrichment sites, which takes into account the distribution of SNPs of the chip itself in each chromosome. Of course, finding a suitable scanning unit will help determine the location of the target gene for this method. Figure 7A and B shows the dataset of the relative frequency distribution of polymorphic SNPs when the window screen size was $10 \mathrm{~KB}$ and $10 \mathrm{M}$, respectively. It is indicated that a window screen size of $10 \mathrm{~KB}$ has an influence on the judgment of the position of the target gene because the $P$ value is too high. When the window screen size is $10 \mathrm{M}$, more enrichment peaks are shown owing to the relative decrease of the $P$ value. Thus, the best screen window size is $1 \mathrm{M}$ for genotypes from the wheat $660 \mathrm{~K}$ SNP chip. In addition, Figure $7 \mathrm{C}$ shows a dataset of the relative frequency distribution of polymorphic SNPs for detecting resistance gene $\operatorname{YrM8664-3}$ (Chao et al. 2018) to verify the usefulness of this method. An enrichment peak appears on 4A, which is consistent with the mapping result. Through the above experiment and discussion, this method can be used as a preliminary tool to determine the possible location of the target gene. Of course, precisely mapping a target gene requires genotyping and phenotyping each individual in a segregating population and conducting genetic analysis.

Markers and associated genes. TraesCS4B01G266700, associated with $I L P-4 B 01 G 266700$, expressed a GRAS transcription factor protein. GRAS genes have been proven to be related to plant disease resistance (Mayrose et al. 2006). TraesCS4B01G266900 and TraesCS4B01G271700, associated with ILP-4B01G266900 and ILP-4B01G271700, expressed F-box family protein. The F-box family genes were commonly found to be associated with the leucinerich repeat motif, which is a classic disease-resistant conserved motif (National Center for Biotechnology Information 2019). These three disease-related genes have the ILP between the resistant and susceptible cultivars, and the associated markers linked to PmTx45 can be used to conduct a real-time quantitative PCR assay to verify whether it plays a role in the resistance to powdery mildew in later experiments.

PmTx45 may be a novel recessive moderate powdery mildew resistance gene, and it has potential application value in breeding. To date, there is no powdery mildew resistance gene reported on 4BL. PmTx45 may be a novel powdery mildew resistance gene. The application value of $P m T x 45$ is shown in the following aspects. First, PmTx45 has seedling resistance to HY5, which is virulent to $77 \%$ of tested varieties. If the seedling resistant varieties are planted in the origins of disease epidemics, they can inhibit inoculum rates to control disease epidemics, effectively year-round. If PmTx45 is widely carried by the cultivars planted in the origins of epidemics, it could suppress the prevalence of HY5 even with a moderate resistance. Second, PmTx45 is a recessive resistance gene, which means that resistant individuals must be homozygous to be conducive to the breeding process. In addition, further study of recessive moderate powdery mildew seedling resistance gene PmTx45 may also provide new ideas for understanding the interaction between plants and pathogens as well as the immune mechanism of plants. Finally, a pyramiding breeding strategy should be used to combine multiple race-specific resistance genes and nonrace-specific genes to achieve broad resistance. The detection rate of PmTx45 in wheat varieties was rare, and the location of PmTx45 is novel compared with the known powdery mildew resistance genes. The finding of $P m T x 45$ resistance provides a new genetic locus for molecular breeding against wheat powdery mildew, and combining PmTx45 with other Pm genes will be beneficial to developing durable powdery mildew-resistant wheat cultivars. In summary, PmTx45 is a potentially novel gene that is valuable for powdery mildew resistance breeding.

\section{LITERATURE CITED}

Cao, S. Q., Sun, Z. Y., Feng, J., Wang, W. J., Jia, Q. Z., Huang, J., Zhang, B., Jin, S. L., Zhang, Y., H., and Luo, H. S. 2017. Analysis of stripe rust resistance of selected series winter wheat cultivars. J. Triticeae Crops 2: 268-274 (In Chinese).

Chao, K. X., Yang, J. Y., Liu, H., Jing, J. X., Ma, D. F., Li, Q., and Wang, B. T. 2018. Genetic and physical mapping of a putative Leymus mollis-derived stripe rust resistance gene on wheat chromosome 4A. Plant Dis. 102: 1001-1007.

Choi, S. R., Teakle, G. R., Plaha, P., Kim, J. H., Allender, C. J., Beynon, E., Piao, Z. Y., Soengas, P., Han, T. H., King, G. J., Barker, G. C., Hand, P., Lydiate, 
D. J., Batley, J., Edwards, D., Koo, D. H., Bang, J. W., Park, B. S., and Lim, Y. P. 2007. The reference genetic linkage map for the multinational Brassica rapa genome sequencing project. Theor. Appl. Genet. 115:777-792.

Cui, F., Zhang, N., Fan, X., Zhang, W., Zhao, C., Yang, L., Pan, R., Chen, M., Han, J., Zhao, X., Ji, J., Tong, Y., Zhang, H., Jia, J., Zhao, G., and Li, J. 2017. Utilization of a Wheat660K SNP array-derived high-density genetic map for high-resolution mapping of a major QTL for kernel number. Sci. Rep. 7:3788.

Fu, B., Chen, Y., Li, N., Ma, H., Kong, Z., Zhang, L., Jia, H., and Ma, Z. 2013. PmX: A recessive powdery mildew resistance gene at the Pm4 locus identified in wheat landrace Xiaohongpi. Theor. Appl. Genet. 126:913-921.

Griffey, C. A., Das, M. K., and Stromberg, E. L. 1993. Effectiveness of adultplant resistance in reducing grain yield loss to powdery mildew in winter wheat. Plant Dis. 77:618-622.

He, C., Holme, J., and Anthony, J. 2014. SNP genotyping: The KASP assay. Methods Mol. Biol. 1145:75-86.

Hsam, S. L. K., Huang, X. Q., and Zeller, F. J. 2001. Chromosomal location of genes for resistance to powdery mildew in common wheat (Triticum aestivum L. em Thell.) 6. Alleles at the Pm5 locus. Theor. Appl. Genet. 102:127-133.

Hua, W., Liu, Z., Zhu, J., Xie, C., Yang, T., Zhou, Y., Duan, X., and Sun, Q. 2009. Identification and genetic mapping of $P m 42$, a new recessive wheat powdery mildew resistance gene derived from wild emmer (Triticum turgidum var. dicoccoides). Theor. Appl. Genet. 119:223-230.

Huang, X. Q., Wang, L. X., Xu, M. X., and Roder, M. S. 2003. Microsatellite mapping of the powdery mildew resistance gene Pm5e in common wheat (Triticum aestivum L.). Theor. Appl. Genet. 106:858-865.

Jia, J. Z., and Zhao, G. Y. 2016. Wheat660 SNP array developed by CAAS. http://wheat.pw.usda.gov/ggpages/topics/Wheat660_SNP_array_developed_ by_CAAS.pdf

Kosambi, D. D. 1943. The estimation of map distances from recombination values. Ann. Hum. Genet. 12:172-175.

Leath, S., and Bowen, K. L. 1989. Effects of powdery mildew, triadimenol seed treatment, and triadimefon foliar sprays on yield of winter wheat in North Carolina. Phytopathology 79:152-155.

Ma, P., Xu, H., Luo, Q., Qie, Y., Zhou, Y., and Xu, Y. 2014. Inheritance and genetic mapping of a gene for seedling resistance to powdery mildew in wheat line x3986-2. Euphytica 200:149-157.

Mayrose, M., Ekengren, S. K., Melech-bonfil, S., Martin, G. B., and Sessa, G. 2006. A novel link between tomato GRAS genes, plant disease resistance and mechanical stress response. Mol. Plant Pathol. 7:593-604.

McIntosh, R. A., Dubcovsky, J., Rogers, W. J., Morris, C., and Xia, X. C. 2017. Catalogue of gene symbols for wheat: 2017 supplement. https://shigen.nig.ac.jp/wheat/komugi/genes/macgene/supplement2017.pdf

Michelmore, R. W., Paran, I., and Kesseli, R. V. 1991. Identification of markers linked to disease-resistance genes by bulked segregant analysis: A rapid method to detect markers in specific genomic regions by using segregating populations. Proc. Natl Acad. Sci. 88:9828-9832.

Mundt, C. C., Cowger, C. C., and Garrett, K. A. 2002. Relevance of integrated disease management to resistance durability. Euphytica 124:245-252.

National Center for Biotechnology Information. 2019. F-box domain. https:// www.ncbi.nlm.nih.gov/Structure/cdd/cddsrv.cgi?ascbin $=8 \&$ maxaln $=10 \&$ seltype $=2 \&$ uid $=$ pfam 00646

Nelson, R., Wiesner-Hanks, T., Wisser, R., and Balint-Kurti, P. 2018. Navigating complexity to breed disease-resistant crops. Nat. Rev. Genet. 19:1-13.

Niewoehner, A. S., and Leath, S. 1998. Virulence of Blumeria graminis f. sp. tritici on winter wheat in the eastern United States. Plant Dis. 82:64-68.

Parks, R., Carbone, I., Murphy, J. P., and Cowger, C. 2009. Population genetic analysis of an Eastern U.S. wheat powdery mildew population reveals geographic subdivision and recent common ancestry with U.K. and Israeli populations. Phytopathology 99:840-849.
Parks, R., Carbone, I., Murphy, J. P., Marshall, D., and Cowger, C. 2008. Virulence structure of the Eastern U.S. wheat powdery mildew population. Plant Dis. 92:1074-1082.

Ramirez-Gonzalez, R. H., Uauy, C., and Caccamo, M. 2015. PolyMarker: A fast polyploid primer design pipeline. Bioinformatics 31:2038-2039.

Rong, J. K., Millet, E., Manisterski, J., and Feldman, M. 2000. A new powdery mildew resistance gene: Introgression from wild emmer into common wheat and RFLP-based mapping. Euphytica 115:121-126.

Schneider, D. M., Heun, M., and Fischbeck, G. 1991. Inheritance of the powdery mildew resistance gene $P m 9$ in relation to $P m 1$ and $P m 2$ of wheat. Plant Breed. 107:161-164.

Semagn, K., Babu, R., Hearne, S., and Olsen, M. 2014. Single nucleotide polymorphism genotyping using Kompetitive Allele-Specific PCR (KASP): Overview of the technology and its application in crop improvement. Mol. Breed. 33:1-14.

Sheng, B. Q. 1988. Using reactive type record wheat seedling powdery mildew. Plant Prot. 1:49 (In Chinese).

Singh, R. P., Hodson, D. P., Huerta-Espino, J., Jin, Y., Njau, P., Wanyera, R., Herrera-Foessel, S. A., and Ward, R. W. 2008. Will stem rust destroy the world's wheat crop? Adv. Agron. 98:271-309.

van Ooijen, J. W. 2006. JoinMap 4.0: Software for the calculation of genetic linkage maps in experimental populations. Kyazma B.V., Wageningen, Netherlands.

Voorrips, R. 2002. MapChart: Software for the graphical presentation of linkage maps and QTLs. J. Hered. 93:77-78.

Wang, M., Wang, S., Liang, Z., Shi, W., Gao, C., and Xia, G. 2018. From genetic stock to genome editing: Gene exploitation in wheat. Trends Biotechnol. 36:160-172.

Wei, H., Fu, Y., and Arora, R. 2005. Intron-flanking EST-PCR markers: From genetic marker development to gene structure analysis in Rhododendron. Theor. Appl. Genet. 111:1347-1356.

Wu, J., Huang, S., Zeng, Q., Liu, S., Wang, Q., Mu, J., Yu, S., Han, D., and Kang, Z. 2018. Comparative genome-wide mapping versus extreme poolgenotyping and development of diagnostic SNP markers linked to QTL for adult plant resistance to stripe rust in common wheat. Theor. Appl. Genet. 131:1777-1792

Wu, J., Liu, S., Wang, Q., Zeng, Q., Mu, J., Huang, S., Yu, S., Han, D., and Kang, Z. 2017. Rapid identification of an adult plant stripe rust resistance gene in hexaploid wheat by high-throughput SNP array genotyping of pooled extremes. Theor. Appl. Genet. 131:1-16.

Xia, Y., Zhou, Y. 1., Duan, X. Y., and Liu, X. M. 2005. Monitoring of Blumeria graminis f. sp. tritici isolates to triadimefon in 2002 and establishment of pathogen base-line sensitivity to kresoxim-methyl. Acta Phytopathologica Sin. 35:74-78 (In Chinese).

Xiao, M., Song, F., Jiao, J., Wang, X., Xu, H., and Li, H. 2013. Identification of the gene Pm47 on chromosome 7BS conferring resistance to powdery mildew in the Chinese wheat landrace Hongyanglazi. Theor. Appl. Genet. 126:1397-1403

Yan, G. P., Chen, X. M., Line, R. F., and Wellings, C. R. 2003. Resistance gene-analog polymorphism markers co-segregating with the $\mathrm{Yr} 5$ gene for resistance to wheat stripe rust. Theor. Appl. Genet. 106:636-643.

Yang, L., Jin, G., Zhao, X., Zheng, Y., Xu, Z., and Wu, W. 2007. PIP: A database of potential intron polymorphism markers. Bioinformatics 23: 2174-2177.

Yin, J., Fang, Z., Sun, C., Zhang, P., Zhang, X., Lu, C., Wang, S., Ma, D., and Zhu, Y. 2018. Rapid identification of a stripe rust resistant gene in a spaceinduced wheat mutant using specific locus amplified fragment (SLAF) sequencing. Sci. Rep. 8:3086.

Zou, C., Wang, P., and Xu, Y. 2016. Bulked sample analysis in genetics, genomics and crop improvement. Plant Biotechnol. J. 14:1941-1955. 